\title{
Stitched Ground Planes for Textile Antenna Application: An Experimental Study
}

\author{
Abraham T. Wiri \\ Department of Electrical Engineering, Rivers State University, Port Harcourt, Nigeria \\ Email: wiri.abraham@ust.edu.ng
}

How to cite this paper: Wiri, A.T. (2021) Stitched Ground Planes for Textile Antenna Application: An Experimental Study. Open Journal of Antennas and Propagation, 9, 11-25.

https://doi.org/10.4236/ojapr.2021.92002

Received: April 11, 2021

Accepted: April 26, 2021

Published: April 29, 2021

Copyright (c) 2021 by author(s) and Scientific Research Publishing Inc. This work is licensed under the Creative Commons Attribution International License (CC BY 4.0).

http://creativecommons.org/licenses/by/4.0/

\begin{abstract}
This paper presents an application of stitched ground plane for microstrip patch antenna design. In this work Matlab interface to computer embroidery techniques were used to implement the felt and denim substrates on microstrip patch antenna. These antennas were simulated using a commercial full 3D electromagnetic CST Microwave Studio 2019. A method to optimize the stitch patterns with conductive thread for antenna ground plane for $2.45 \mathrm{GHz}$ industrial, scientific, and medical (ISM) band and $5 \mathrm{GHz}$ wearable wireless local area networks (WLAN) frequencies was achieved. Rigid and flexible wearable antennas (microstrip patch antennas) were fabricated using the stitched ground plane. The electrical resistance was reduced between the meshes during the stitching design process. Results in terms of bandwidth, radiation patterns and reflection coefficients $\left(S_{11}\right)$ are presented.
\end{abstract}

\section{Keywords}

Stitched, Ground Plane, Embroidery, Textile Antennas, Conductive Thread

\section{Introduction}

Wearable antennas are designed and meant to be part of clothing for application on the human body or animal. Wearables have attracted industry interest due to their applications and increasing demands in the wireless world. Wearables are devices worn on the body that uses advanced circuitry and have independent processing potential. Wearables are part of daily functionalities for data analysis and communication between smartphones and the body. These devices make use of a combination of sensors, machine learning and data analysis to provide information to the consumer's body.

The commercial market has various types of wearables devices including fitness trackers, smartwatches, smart glasses wearable cameras, gesture devices, lo- 
cation trackers, body sensors, and smart clothing. The devices are used for various applications ranging from healthcare to sporting notifications [1]-[6]. The wearable antenna is a bond that integrates cloth into a communication system, making electronic devices less obtrusive. To achieve good results, wearable antennas must be thin, lightweight, low maintenance, robust, inexpensive, and easily integrated into radiofrequency.

Microstrip patch antennas have been largely used in applications where low costs, lightweight properties, and low-profile antennas are desirable. Other advantages easy integration with microwave integrated circuits and body-worn wireless communication equipment. There is various way of feeding the microstrip patch antenna which includes coaxial probe feed, microstrip line, inset fed, aperture coupling and proximity coupling. Most designs of microstrip antenna are fed by simple coaxial probe because of ease of fabrication. In this paper the rectangular microstrip patch antennas are fed by a microstrip line with inset feed. The inset feed is used for microstrip patch antenna to improve the impedance match with planar feed configuration. The input impedance of microstrip patch antenna depends on the feed position for probe feed or the microstrip feed inset [7] [8] [9] [10] [11].

A patch antenna with enhanced gain, bandwidth hand directivity has been developed by using micromachining technique for RFID applications. For compacting the antenna, dielectric constant of 11.9 is taken. Performance of the antenna has been collated while using single dielectric layers, after that they used two dielectric layers of substrate (silicon/air) and then expanded the substrate layers to three (silicon/air/silicon). Finally, it was concluded that better results in terms of bandwidth, gain and directivity can be achieved using multilayer substrate [12].

Several authors for the design of textile antennas used different conductive materials and dielectric substrates. Textile antenna has been fabricated by various methods including weaving, knitting, lamination, printing, and embroidery [13]-[18]. An embroidery technique was chosen because of the integration of garments with stitched antennas. Embroidery is fast and flexible in creating new patterns and make integrating radio frequency systems into clothing/garments for wearable applications. This focuses on providing a better interconnection between the mesh nodes and reducing the discontinuities of the stitched patch. This work also optimizes stitched patterns and reduces overstitching of the mesh. One specific advantage of stitched antennas is their simplicity of construction. They can be retrofitted to existing garment designs and there is a high level of flexibility. The work develops methods for making use of two flexibility by considering a set of problems with many variables and seeking optimal solutions with methods.

This paper presents the method of implementing stitched ground plane design using computerized aided design (CAD) software-controlled embroidery machine. This technique was interfaced with MATLAB to produce desired fabric-based 
stitched antennas. These designs were carried out for two frequencies: $2.45 \mathrm{GHz}$ and $5 \mathrm{GHz}$. A single layer embroidery was used to realize a higher conductive textile surface. Four antenna samples were fabricated and evaluated all microstrip patch antenna like solid patch with solid ground plane, meshed patch with meshed ground plane, solid patch on meshed ground plane and solid patch on denim and felt substrate.

The rest of this paper is structured as follows: the designed method is discussed in Section 2. The mechanism of embroidery is also addressed in Section 3. In Section 4 the return losses and radiation patterns are presented. Section 5 concludes the work.

\section{Antenna Design and Structure}

\subsection{Design Equations}

The following formulae for the antenna design are taken from Balanis [7] [8] [9] [10].

Microstrip patch antenna width

$$
W=\frac{C}{2 f_{0} \sqrt{\frac{\varepsilon_{r}+1}{2}}}
$$

where $c=\frac{1}{\sqrt{\mu_{0} \varepsilon_{0}}}$

Effective dielectric constant

$$
\begin{gathered}
\varepsilon_{\text {reff }}=\frac{\varepsilon_{r}+1}{2}+\frac{\varepsilon_{r}-1}{2}\left\lceil 1+12 \frac{h}{W}\right]^{-1 / 2} \\
\varepsilon_{\text {reff }}\left(\frac{W}{h} \gg 1\right)
\end{gathered}
$$

Effective length

$$
L_{\text {eff }}=L+2 \Delta L
$$

The actual length $L$ of the microstrip patch antenna is given as

$$
L=\frac{\lambda_{0}}{2}=2 \Delta L
$$

Normalized extension length

$$
\frac{\Delta L}{h}=0.412 \frac{\left(\varepsilon_{\text {reff }}+0.3\right) \frac{W}{h}+0.264}{\left(\varepsilon_{\text {reff }}-0.258\right) \frac{W}{h}+0.8}
$$

Resonant frequency

$$
\left(f_{r}\right)_{010}=\frac{1}{2 L \sqrt{\varepsilon_{r}} \sqrt{\varepsilon_{r} \mu_{0}}}
$$

Ground dimension: for a good and practical designs, a finite ground plane is 
needed apart from having an essential substrate. The dimension of the ground plane may be given as

$$
\begin{aligned}
& L_{g}=6 h+l \\
& W_{g}=6 h+w
\end{aligned}
$$

\subsection{Input Impedance}

The transmission-line model represents the patch as a low-impedance line whereby the width of the patch determines the impedance and the effective dielectric constant. A microstrip patch consists of parallel plate radiation conductance and capacitive susceptance that loads both the radiating edges of the patch. The radiation conductance for a parallel-plate radiator is defined as [9]:

$$
\begin{gathered}
G=\frac{\pi W}{\eta \lambda_{0}}\left[1-\frac{(k H)^{2}}{24}\right] \\
R_{e}=\frac{1}{2 G}
\end{gathered}
$$

The computed value of $G$ was $2.49 \mathrm{~m} \Omega$ and $R_{e}$ the input resistance at the edge, is $200 \Omega$ with $y_{0}$ inset distance. The capacitive susceptance in relation to the effective strip extension is given as

$$
B=0.01668 \frac{\Delta}{H} \frac{W}{\lambda} \varepsilon_{\text {eff }}
$$

Microstrip antenna is fed from the edge using an inset line where the gap on either side of strip line is equal to its width. The feed location $y_{0}$ was computed from Equations (9)-(13) using a radian angle measure.

$$
\begin{gathered}
R_{i}=R_{e} \sin ^{4} \frac{\pi y_{0}}{L}, 0 \leq y_{0} \leq \frac{L}{2} \\
y_{0}=\frac{L}{\pi} \sin ^{-1}\left(\frac{R_{i}}{R_{e}}\right)^{1 / 4}
\end{gathered}
$$

Computed values of $50 \Omega$ feed inset, $y_{0}$ for $5 \mathrm{GHz}$ was $3.5 \mathrm{~mm}$ and for 2.45 $\mathrm{GHz}$ the value is given as $7.5 \mathrm{~mm}$. The values were compared to the computed values in [9].

\subsection{Antenna Structure}

This section presents a simulation study of a set microstrip patch antennas with different ground plane configurations. Simulations were performed using CST Microwave Studio. This software package uses the FIT method for electromagnetic simulations. The structure and dimension of the proposed microstrip patch antenna is inspired from Balanis [7]. The design geometry is shown in Figure 1. The ground plane covers the entire side of the substrate and is made of copper sheet of $0.035 \mathrm{~mm}$ thickness. The radiating element is designed with the same thickness copper. Relative permittivity of FR4 $\left(\varepsilon_{r}=4.4\right.$ and loss tangent 


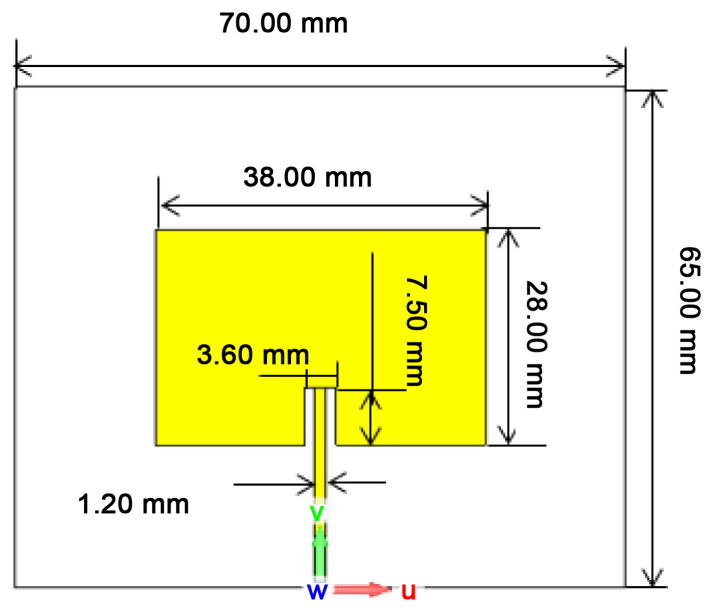

Figure 1. The dimensions of the antennas examined: microstrip inset feed.

$\delta=0.018$ ). The ground plane size is $W_{g} \times L_{g}=70 \mathrm{~mm} \times 65 \mathrm{~mm}$ of substrate height $h_{s}=1.4 \mathrm{~mm}$ is used for all the antennas. The size of the patch is $W_{p} \times L_{p}=38 \mathrm{~mm} \times 28 \mathrm{~mm}$. The feedline has a characteristic impedance of $50 \Omega$ coaxial SMA for excitation of the antennas.

The dimensions of the microstrip patch antennas were approximated from equations [8]. The next patch antenna was designed to operate at $5 \mathrm{GHz}$ and the dimensions are listed in Table 1. The proposed antennas are constructed with two different substrates: FR4 substrate and fabric substrates (denim and felt). The patch and the inset line are made on the same layer.

\subsection{Return Losses}

The return loss is similar to the VSWR that shows matching between feeding system, transmission lines and the antenna. To obtain a perfect matching between the feeding and antenna; $\Gamma=0, \mathrm{RL}=$ infinity, no power is reflected back. When $\Gamma=1, R L=0$ shows that all the incident power is reflected. From the practical applications, VSWR $=2$ is acceptable limit for a good antenna, this corresponds to RL of $9.54 \mathrm{~dB}$. RL greater than $10 \mathrm{~dB}$ is acceptable [7].

$$
\begin{gathered}
\text { Return Loss }=-20 \log (\Gamma) \mathrm{dB} \\
\text { Reflection coefficient }(\Gamma)=\frac{Z_{a}-Z_{l}}{Z_{a}+Z_{l}}
\end{gathered}
$$

where the Input impedance $Z_{a}=R_{a}+j X_{a}, R_{a}$ is the resistance and $X_{a}$ is reactance $Z_{l}$ is the characteristic impedance of the transmission line feeding the antenna $50 \Omega$.

\section{Concept of Computerized Stitching Technique}

Usually textile antennas take the form of planar structures that conform to the human body or follow underlying shape of the garment (e.g. a shirt pocket). Several material properties influence the working of a textile antennas. Permittivity 
Table 1. Microstrip antenna dimensions and parameters at $5 \mathrm{GHz}$ [7].

\begin{tabular}{cc}
\hline Operating frequency, $f$ in $\mathrm{GHz}$ & 5 \\
Dielectric constant & 4.4 \\
Length of the patch, $L_{P}$ in $\mathrm{mm}$ & 14 \\
Width of the patch, $W_{P}$ in $\mathrm{mm}$ & 18.42 \\
Position of inset feed point, $y_{p}$ in mm & 3.5 \\
Distance between feed \& patch $W_{f p}$ & 1.2 \\
Width of the microstrip feed line $W_{f}$ in mm & 1.2 \\
Height of substrate FR4 in mm & 1.4 \\
Loss tangent of FR4 & 0.018 \\
Ground plane length $L_{g}$ & 44 \\
Ground plane width $W_{g}$ & 48 \\
Thickness $t$ in mm copper sheet & 0.035 \\
Linewidth, $L_{w}$ in $\mathrm{mm}$ & 0.2 \\
\hline
\end{tabular}

and the thickness of the substrate determine the bandwidth and efficiency of a planar microstrip antenna. The use of textiles in antenna design requires characterization of their properties. The accurate characterization of textile substrate properties is fundamental before the antenna design. The conductivity of the ground plane and of the patch is an essential critical factor in determining the efficiency of the antenna [6]. Over the years, many techniques and materials have been employed in producing textile antennas. Textile antennas can be fabricated by several methods, but embroidery is examined in this work.

A digital embroidery machines at Loughborough University was used in stitching the ground plane for microstrip patch antenna designs (see Figure 2). Embroidery was chosen as the method for fabrication of stitched antennas because digital embroidery is fast and flexible in pattern generation and the integration of high frequency systems into clothing. Stitch antennas do not require glue or cutting or lamination processes only stitching the design onto fabric. Antenna designs are converted into a format compatible with an embroidery machine for production. In embroidery patterns are superimposed onto an existing fabric and a stitch design is created. This technology provides high speed, ease of manufacturing, accurate and easily modified stitch antennas. Antennas are automatically integrated into fabric through this process which reduces cost of production. Conductive threads are expensive. A sample quantity of Amberstrand silver yarn costs $£ 1$ per meter [3] and [18]. Embroidery uses specialist conducting thread that have a polymer core and coated with a silver/nickel.

Several authors have addressed the issue of fabricating textile antennas using embroidery [3] and [14]-[19], but Matlab interface to computer embroidery was used in this design. This method is a unique approach to antenna fabrication. Embroidery was used to incorporate RF functions into garments and clothes. The more closely the stitch space the better the electrical connectivity between neighboring stitches and the better the antenna performance. 


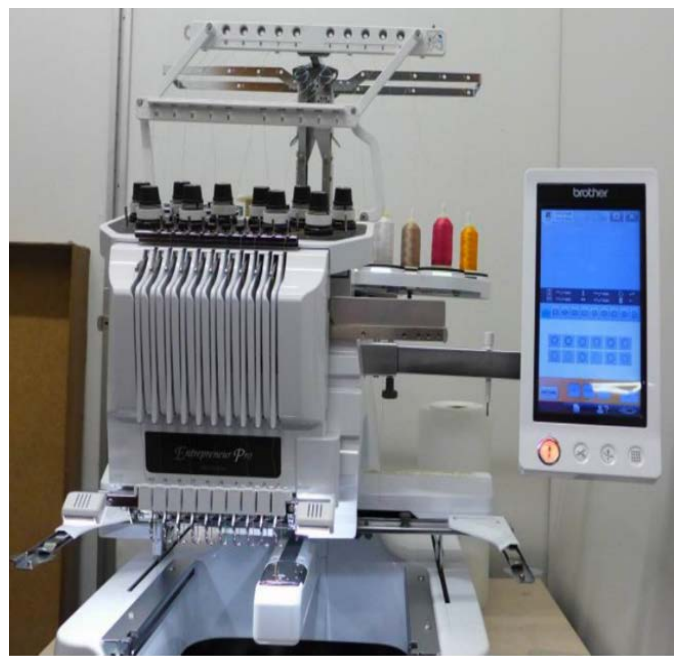

Figure 2. Brother Pr1000e embroidery machine at Loughborough university.

Figure $3(\mathrm{~b})$ is a sketch of the lock stitch formation comprising; conductive thread (1) and non-conductive thread (2). To create stitch pattern on a substrate material two threads are required. The stitched antennas in this work were embroidered using textile conductive thread (Liberator or Amber strand) on denim or felt substrate. Conductive thread was set up in the bobbin of the embroidery machine; see Figure 3(b) in the blue in this study as in Figure 3(a) because of tension on the conductive thread. Using the conductive thread in the bobbin allows the thread to be straight. The upper thread was a non-conductive polyester yarn that goes into the substrate material during embroidery. The principle used in creating a lock stitched pattern employed by embroidery is the needle containing the upper thread is sunk through the fabric material into the lower section of the machine where the conductive thread is placed in the bobbin. A hanger hooks onto the upper thread just after the thread goes into the needle. A rotating mechanism loops the upper thread around the bobbin and then a feed dog pulls the extra upper thread available around the bobbin back to the top of the fabric. The conductive thread is then pulled along the bottom of the substrate forming a lock stitch. In the process of embroidery, small portion of oil was applied to Liberator thread and Amberstrand so that the threads would not unravel or break during the stitching process. This makes the thread filament stick together and reducing the unravel loss. Single-layer embroidery was used to realize higher conductive textile surfaces giving a lower DC resistance [3] and [17] [18]. In all the fabrications of wire antennas, planar wire antennas and microstrip antennas single layer stitching densities were employed. There are detailed works relating to fully wearable textile antennas using computerized embroidery techniques at different frequencies [19].

\section{Predicted and Measured Results}

In this section, copper tape of thickness $0.035 \mathrm{~mm}$ has been used design the 


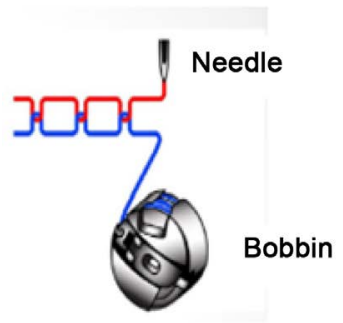

(b)

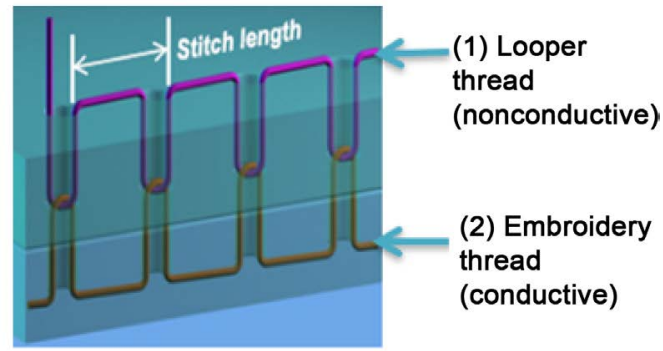

(a)

Figure 3. (a) Sketch of the lock stitches and (b) Bobbin with top thread and looper thread using a single layer technique (from [17]).

patch and ground plane of the antenna. The metallic patch and ground plane were fabricated using etching. The metallic mesh of the ground plane has a thickness of $0.035 \mathrm{~mm}$. The copper ground plane of the patch antenna was replaced with metallic mesh, fabric substrates of denim $=0.85 \mathrm{~mm}$ thickness single layer and felt $=1 \mathrm{~mm}$ thickness single layer. Denim and felt fabric were used for the antenna substrate. Characterization of these substates were carried using a split post dielectric resonator [20] and they exhibit the following relative permittivity and loss tangent: results for the single layer denim are thickness $0.85 \mathrm{~mm}$ $\varepsilon_{r}=1.97 \tan \delta=0.07$. For felt fabric results are thickness $1 \mathrm{~mm}, \varepsilon_{r}=1.2$ and $\tan \delta=0.0013$. The microstrip patch antenna sample made of solid copper of thickness $0.035 \mathrm{~mm}$ shown in Figure 4(b) and Figure 4(d) were soldered. In the designs of stitched ground plane of Figure 4(a) and Figure 4(c), the yarn follows a straight line and all the nodes (current path) are electrically connected.

The ground planes represented in Figure 5 were designed and fabricated in this work. Figure 5(a) is a solid patch on meshed ground plane (MPG1) of dimension $2 \mathrm{~mm} \times 2 \mathrm{~mm}$. Figure $5(\mathrm{~b})$ is a solid patch on a solid ground plane (PA1). The solid ground planes were replaced using felt and denim. Figure 5(c) antenna PA3 is a solid patch and meshed ground (using conductive thread on denim material). Figure 5(d) antenna PA4 is a solid patch on FR4 substrate and conductive thread stitched on felt fabric as a ground plane.

The resonant frequency and reflection coefficient of all the designed samples 
of antennas were performed the laboratory at Loughborough University using Anritsu 37397 DVector Network Analyser to verify the theoretical analysis. The simulated and measured reflection coefficient is shown in Figure 6. The reflection coefficient result confirmed an impedance bandwidth of $85 \mathrm{MHz}$ covering $2.45 \mathrm{GHz}$ of the Wi-Fi band $(2.4-2.485 \mathrm{GHz})$. Measured $\mathrm{S}_{11}$ is $-21.48 \mathrm{~dB}$ at 2.45 $\mathrm{GHz},-10 \mathrm{~dB}$ Bandwidth $49 \mathrm{MHz}$ and simulation $\mathrm{S}_{11}$ is $-25.81 \mathrm{~dB}$ at $2.46 \mathrm{GHz}$ $-10 \mathrm{~dB}$ bandwidth $87 \mathrm{MHz}$.

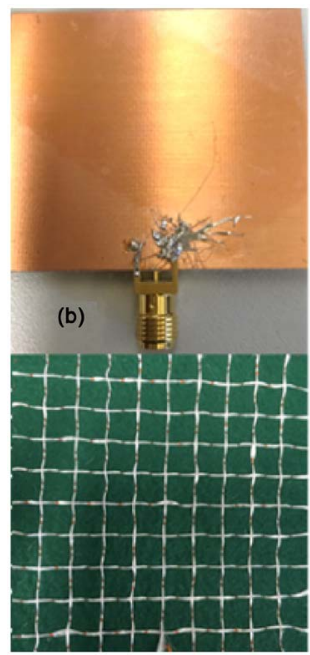

(a)

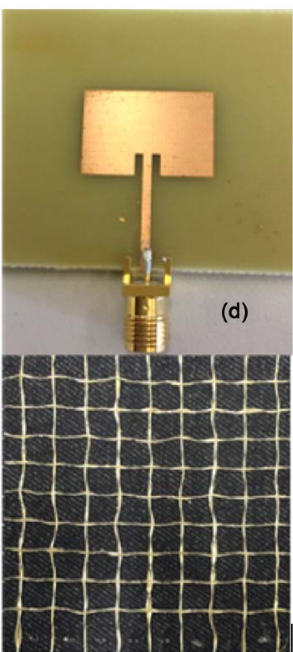

(c)

Figure 4. Photos of fabricated prototypes of microstrip patch antenna (a) stitched ground on felt, (b) etched copper ground, (c) stitched ground on Denim substrate and (d) etched radiating patch on FR4 substrate.

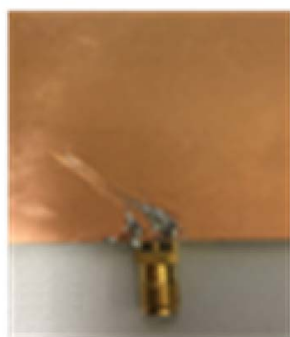

(b)

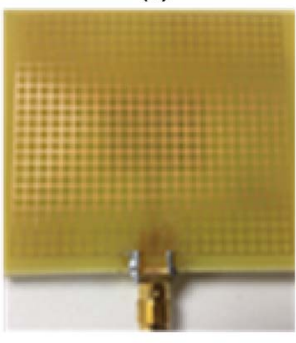

(a)

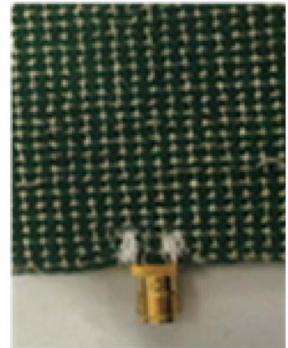

(d)

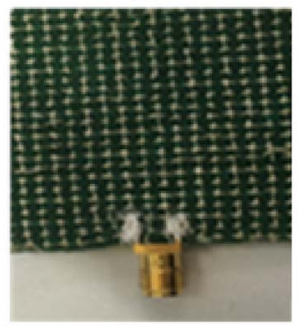

(c)

Figure 5. (a) MPG1 meshed ground, (b) PA1 etched copper prototype, (c) PA3 on denim fabric and (d) PA4 on felt substrate. 


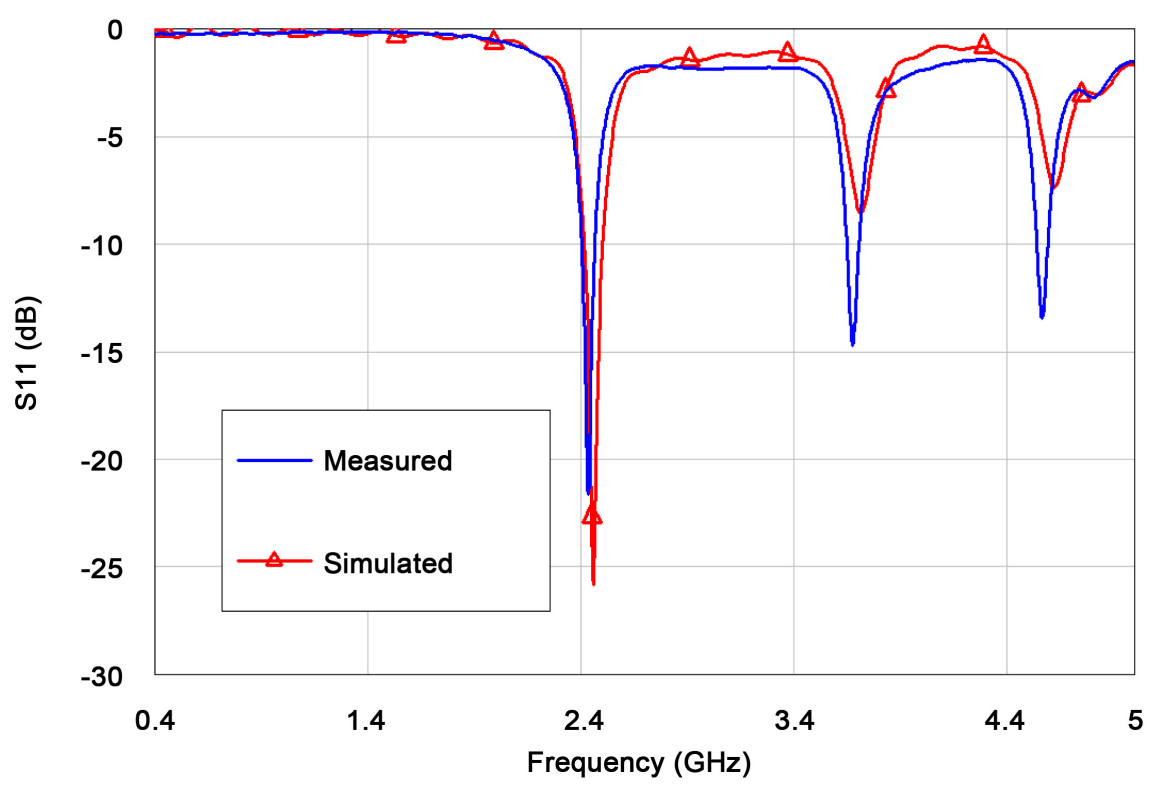

Figure 6. Comparison between simulation and measurement of the proposed microstrip patch (inset feed) by means of the $S_{11}$ plot.

\subsection{Comparison of Patches with Meshed and Solid Ground Planes}

The measured input reflection $\left(\mathrm{S}_{11}\right.$-parameter) of the antenna samples MGP4 and PA1 is shown in Figure 7. The antenna sample MGP4 is solid patch on a meshed ground plane while PA1 is solid patch on a solid ground plane. The measured $\mathrm{S}_{11}$ for of MGP4 is $-20.2 \mathrm{~dB}$ at $4.72 \mathrm{GHz}-10 \mathrm{~dB}$ bandwidth of 260 $\mathrm{MHz}$ (measured) while simulation results give $-15.4 \mathrm{~dB}$ at $4.93 \mathrm{GHz}-10 \mathrm{~dB}$ bandwidth of $140 \mathrm{MHz}$. PA1 simulation result is $-21.4 \mathrm{~dB}$ at $4.97 \mathrm{GHz}$ will -10 $\mathrm{dB}$ bandwidth of $200 \mathrm{MHz}$ and measured $\mathrm{S}_{11}$ of $-25.6 \mathrm{~dB}$ at $4.92 \mathrm{GHz}$ at $-10 \mathrm{~dB}$ bandwidth $200 \mathrm{MHz}$ Antenna sample MGP4 has a directivity of $6.98 \mathrm{dBi}$ while the solid patch PA1 has a directivity of $7.03 \mathrm{dBi}$.

\subsection{Solid Patch with Solid Ground (PA1) and Meshed Patch with Meshed Ground}

Antenna sample PA1 is a solid patch with solid ground plane and antenna sample MGP1 a meshed patch with meshed ground plane. Both have the same dimensions. They are fabricated on an FR4 substrate of $1.4 \mathrm{~mm}$ thickness. The reflection coefficient, $\mathrm{S}_{11}$, of each antenna sample is shown in Figure 8. PA1 simulation $\mathrm{S}_{11}$ result is $-21.4 \mathrm{~dB}$ at $4.97 \mathrm{GHz},-10 \mathrm{~dB}$ bandwidth of $200 \mathrm{MHz}$ and measured $\mathrm{S}_{11}$ is $-25.6 \mathrm{~dB}$ at $4.92 \mathrm{GHz},-10 \mathrm{~dB}$ bandwidth $200 \mathrm{MHz}$ while MGP1 has a measured $\mathrm{S}_{11}$ of $-24.2 \mathrm{~dB}$ at $4.70 \mathrm{GHz}-10 \mathrm{~dB}$ bandwidth of $220 \mathrm{MHz}$ and simulation $\mathrm{S}_{11}$ result at $-26.9 \mathrm{~dB}$ at $4.82 \mathrm{GHz}, 240 \mathrm{MHz}$ The drop in frequency of meshed patch with meshed ground (MGP1) [21] [22] is lower by $4.47 \%$ as compared to PA1. It has a higher impedance bandwidth. The difference between the measured and simulation is due to materials and the SMA connector in the physical fabrications. 


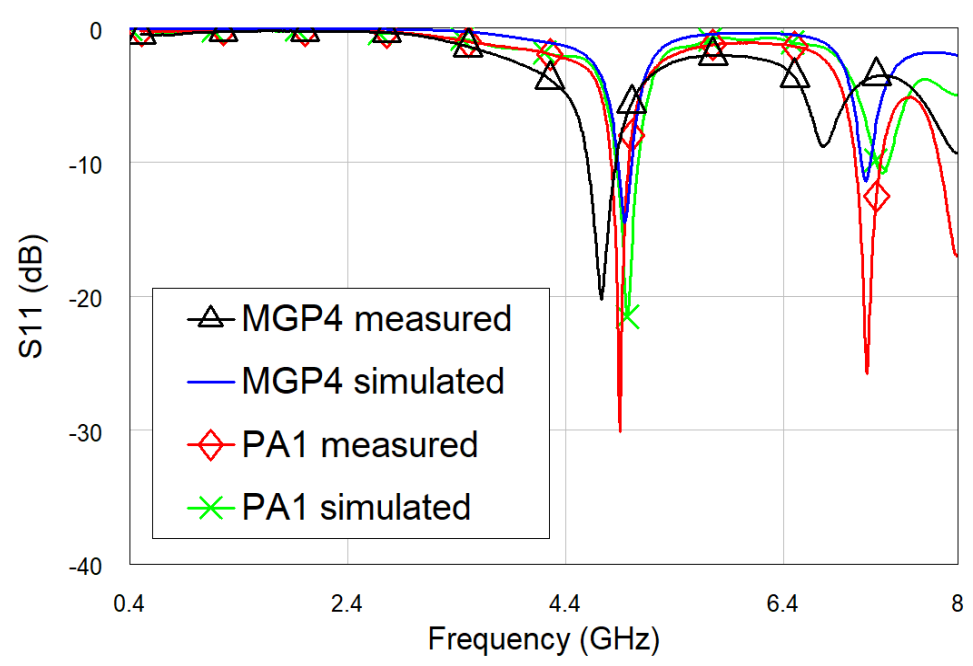

Figure 7. Simulated and measured $\mathrm{S}_{11}$ results of the antenna MGP4 and PA1 (solid patch on meshed and solid ground planes).

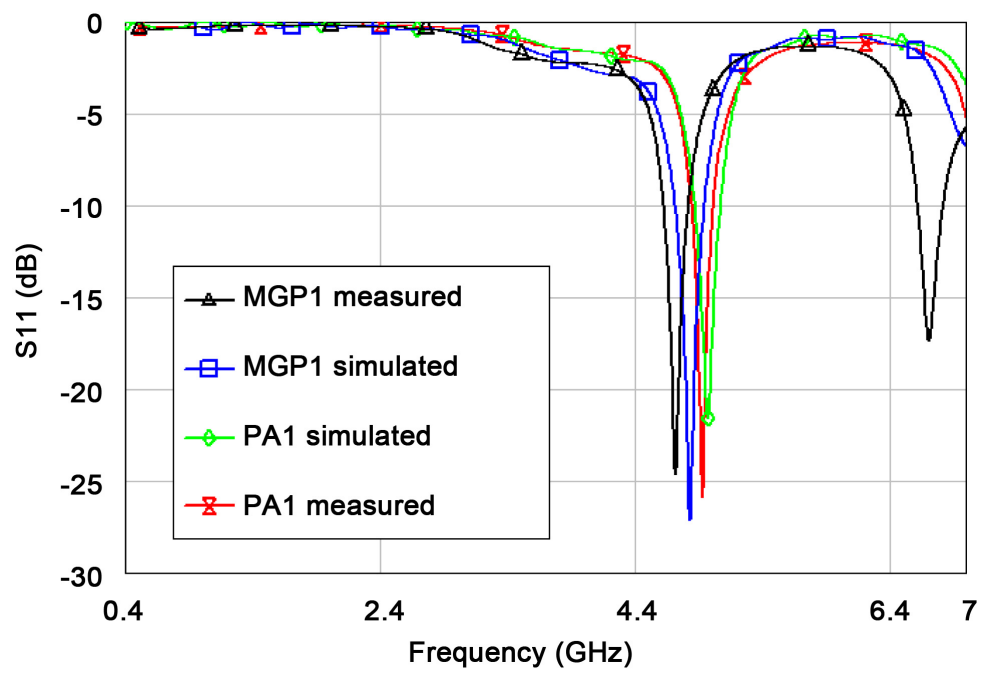

Figure 8. $\mathrm{S}_{11}$ Measured result compared with simulation of solid patch (PA1) with solid ground and meshed patch (MGP1) with meshed ground.

\subsection{Simulated Surface Current for Meshed Ground Plane}

The surface current is strong at the feed point and along the feed length. Currents flow along the vertical lines and the horizontal lines shows an increase in current path as shown in Figure 9 and lowering the fundamental resonant frequency. The current distribution on the triangular mesh is uniformly. The triangular ground plane current paths are longer causing the solid patch antenna with a meshed ground plane to radiate at lower frequency than the solid patch with solid ground plane [22].

The simulated 3-D far field pattern, which controls the antenna's radiation pattern, is illustrated in Figure 10. As can be shown from the figure, the region with the highest gain of $6.83 \mathrm{~dB}$ is coming from the radiating element of the antenna and slowly settles down to $0 \mathrm{~dB}$ further away from the radiating structure. 


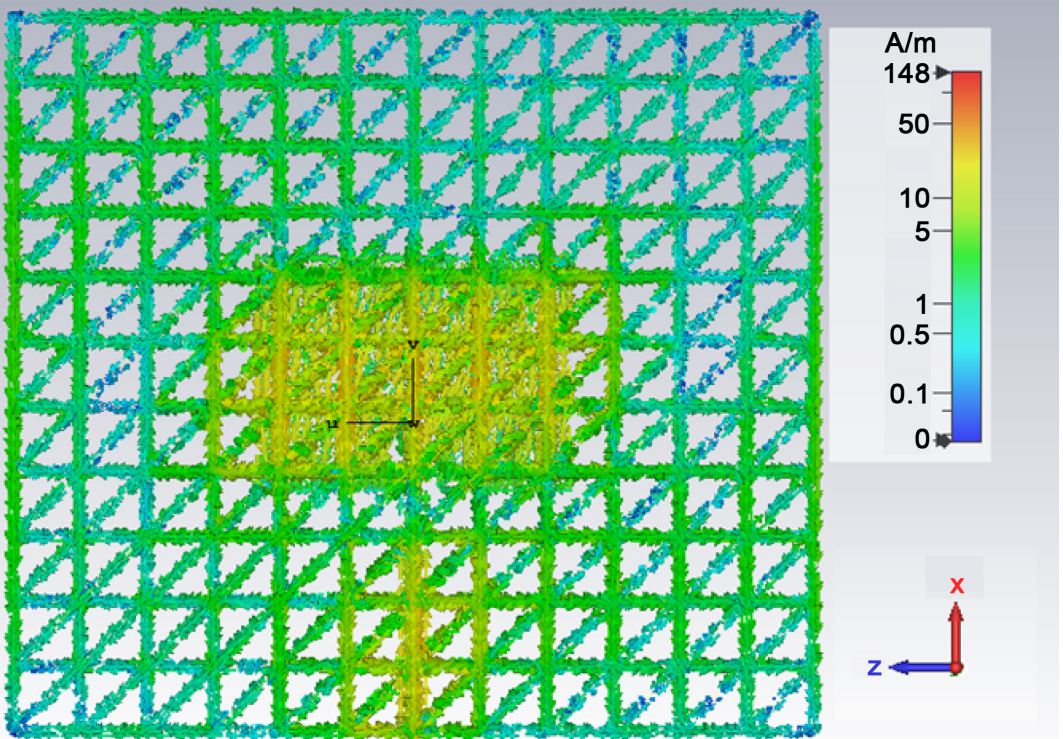

Figure 9. Simulated surface current on meshed ground plane for microstrip patch antenna at $5 \mathrm{GHz}$.

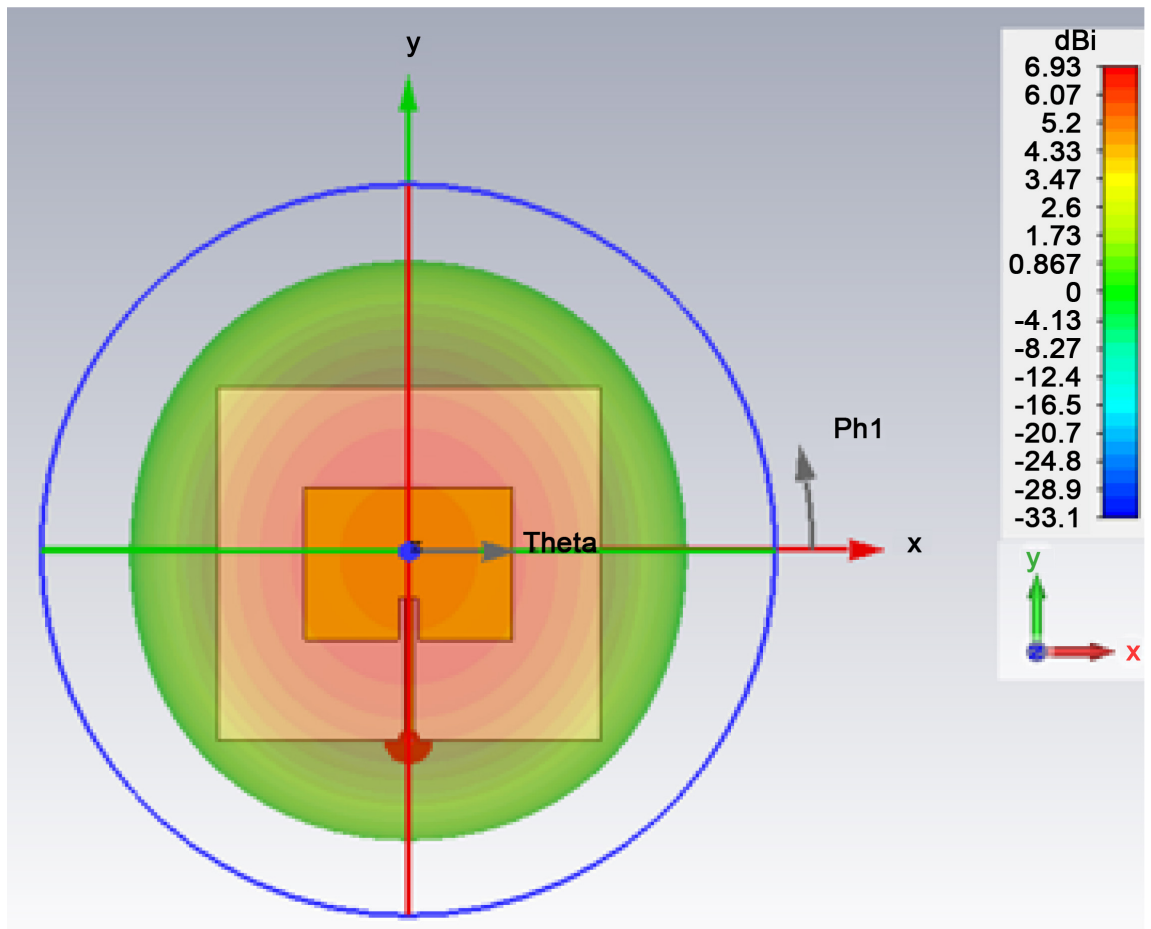

Figure 10. 3D picture of antenna in simulation model at $2.45 \mathrm{GHz}$.

The simulated radiation patterns for a conventional microstrip patch antenna (PA1) and a microstrip patch with meshed ground at their resonant frequencies are shown in Figure 11. Meshing the ground plane does not change the shape of the pattern for the patch antenna but only causes some back radiation will leakage through the ground plane. The patterns are normalized to the peak gain at each frequency. 


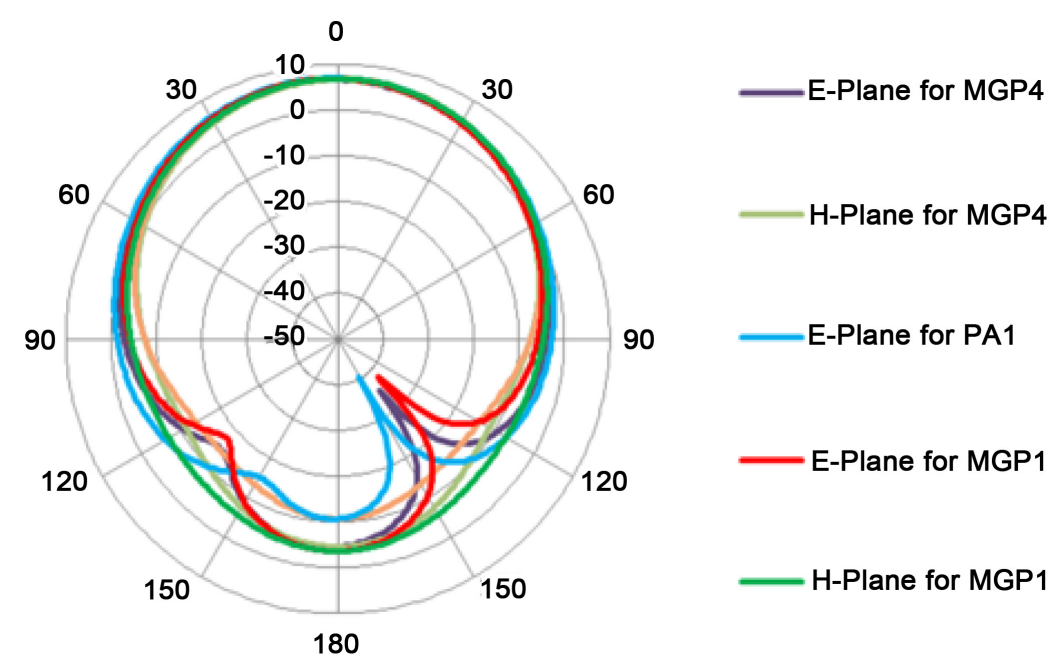

Figure 11. Stimulated radiation patterns of antenna samples at $5 \mathrm{GHz}$.

\section{Conclusions}

This paper has described a technique based on microstrip patch ground plane design using computerized embroidery through MATLAB interface. For the purpose of implementation of the designs, a microstrip patch antenna was designed and stitched on a meshed ground with denim and felt fabric. A practical mesh ground plane was modelled and designed using Matlab interface to computer embroidery. The designs were exported to embroidery machine software for production. Representative samples, used as patch ground planes, were validated. In terms of bandwidth denim substrate used for stitched antennas performed better compared to felt substrate, denim has a firm surface while felt surface fluffy and could be easily crush. Microstrip patch antenna with stitched ground has wider bandwidth than etched ground of the same size. Meshing the ground plane makes the patch antenna to be more flexible and reduces the fabrication cost. Suitable reflection coefficient $\left(S_{11}\right)$ results and gain characteristics were experimental and have been tested from reported literature.

Using the Amber strand with a property of a higher conductivity thread gives a better continuity across the mesh nodes. The method of stitching via the interface reduces the surface disjointedness across the mesh nodes of the ground plane. The interface method reduces the stitching density and electrical resistance between mesh nodes making the antennas to be flexible and wearable. This design has also produced a compact density without breakage along the paths. Integration of the ground plane into antennas reduces the cost of production. The designed antenna can be integrated into human clothing with sensors for wearable applications.

\section{Conflicts of Interest}

The author declares no conflicts of interest regarding the publication of this paper. 


\section{References}

[1] Amft, O. and Sulkowicz, P. (2009) From Backpacks, to Smartphones: Past, Present, and Future of Wearable Computers. IEEE Pervasive Computing, 8, 8-13. https://doi.org/10.1109/MPRV.2009.44

[2] Post, E.R., Orth, M., Russo, M.P.R. and Gerstenfeld, N. (2000) E-Broidery: Design and Fabrication of Textile-Based Computing. IBM Systems Journal, 39, 840-860. https://doi.org/10.1147/sj.393.0840

[3] Acti, T., Chauraya, A., Zhang, S., Whittow, W.G., Seager, R.D., Vardaxoglou, J.C. and Dias, T. (2015) Embroidered Wire Dipole Antennas Using Novel Copper Yarns. IEEE Antennas and Wireless Propagation Letters, 14, 638-641. https://doi.org/10.1109/LAWP.2014.2371338

[4] Mohamadzade, B., Hashmi, R.M., Simorangkir, R.B.V.B., Gharaei, R., Ur Rehman, S. and Abbasi, Q.H. (2019) Recent Advances in Fabrication Methods for Flexible Antennas in Wearable Devices: State of the Art. Sensors, 19, 2312. https://doi.org/10.3390/s19102312

[5] Mantash, M., Tarot, A.C., Collardey, S. and Mahdjoubi, K. (2011) Wearable Monopole Zip Antenna. Electronics Letters, 47, 1266-1267. https://doi.org/10.1049/el.2011.2784

[6] Stoppa, M. and Chiolerio, A. (2014) Wearable Electronics and Smart Textiles: A Critical Review. Sensors, 14, 11957-11992. https://doi.org/10.3390/s140711957

[7] Balanis, C.A. (2016) Antenna Theory Analysis and Design. John Willey and Son's Inc, Hoboken.

[8] Pozar, D.M. (2005) Microwave Engineering New York. Wiley, Hoboken.

[9] Milligan,T. (2005) Modern Antenna Design. Wiley, Hoboken. https://doi.org/10.1002/0471720615

[10] Matin, M.A. and Sayeed, A.I. (2010) A Design Rule for Inset-Fed Rectangular Microstrip Patch Antenna. WSEAS Transactions on Communications, 9, 63-72.

[11] Rajat, A., Ajay, K., Saleem, K., and Sandeep, A. (2013) Finite Element Modeling and Design of Rectangular Patch Antenna with Different Feeding Techniques. Open Journal of Antennas and Propagation, 1, 11-17. https://doi.org/10.4236/ojapr.2013.12004

[12] Saha, R., Maitym, S. and Trigunayat, N. (2015) Enhancement of Gain, Bandwidth and Directivity a Patch Antenna by Increasing Dielectric Layers of the Substrate through Micromachining Technique for RFID Application. 2015 International Conference on Advances in Computer Engineering and Applications, Ghaziabad, 19-20 March 2015, 321-324. https://doi.org/10.1109/ICACEA.2015.7164723

[13] Salonen, P., Sydanheimo, L., Keskilammi, M. and Kivikoski, M. (1999) A Small Planar Inverted-F Antenna for Wearable Applications. The Third International Symposium on Wearable Computers, San Francisco, 18-19 October 1999, 95-100. https://doi.org/10.1109/ISWC.1999.806679

[14] Zeng, W., Shu, L., Li, O., Chen, S., Wang, F. and Tao, X.M. (2014) Fiber-Based Wearable Electronics: A Review of Materials, Fabrication, Devices, and Applications. Advanced Materials, 26, 5310-5336. https://doi.org/10.1002/adma.201400633

[15] Tsolis, A., Whittow, W.G., Alexandridis, A.A. and Vardaxoglou, J.C. (2014) Embroidery and Related Manufacturing Techniques for Wearable Antennas: Challenges and Opportunities. Electronics, 3, 314-338. https://doi.org/10.3390/electronics3020314

[16] Salonen, P., Rahmat-Samii, Y., Hurme, H. and Kivikoski, M. (2004) Dual Band 
Wearable Textile Antenna. IEEE Antennas and Propagation Society Symposium, Monterey, 20-25 June 2004, 463-466. https://doi.org/10.1109/APS.2004.1329674

[17] Acti, T., Zhang, S., Chauraya, A., Whittow, W., Seager, R., Dias, T. and Vardaxoglou, J.C. (2011) High Performance Flexible Fabric Electronics for Megahertz Frequency Communications. 2011 Loughborough Antennas \& Propagation Conference, Loughborough, 14-15 November 2011, 5-8. https://doi.org/10.1109/LAPC.2011.6114088

[18] Zhang, S., Whittow, W., Seager, R., Chauraya, A. and Vardaxoglou, J.C. (2017) Non-Uniform Mesh for Embroidered Microstrip Antennas. IET Microwaves, Antennas \& Propagation, 11, 1086-1091. https://doi.org/10.1049/iet-map.2016.0901

[19] Wiri, A.T. (2019) Automated Design, Optimization, and Simulation of Stitched Antennas for Textile Devices. Ph.D. Dissertation, Loughborough University, Loughborough.

[20] Krupka, J., Geyer, R.G., Baker-Jarvis, J. and Ceremuga, J. (1996) Measurements of the Complex Permittivity of Microwave Circuit Board Substrates Using Split Dielectric Resonator and Reentrant Cavity Techniques. Seventh International Conference on Dielectric Materials, Measurements and Applications, Bath, 23-26 September 1996, 21-24. https://doi.org/10.1049/cp:19960982

[21] Kang, S.H. and Jung, C.W. (2018) Transparent Patch Antenna Using Metal Mesh. IEEE Transactions on Antennas and Propagation, 66, 2095-2100. https://doi.org/10.1109/TAP.2018.2804622

[22] Clasen, G. and Langley, R.J. (2004) Meshed Patch Antennas. IEEE Transactions on Antennas and Propagation, 52, 1412-1416. https://doi.org/10.1109/TAP.2004.830251 